\title{
Percutaneous coronary intervention in cardiac allograft vasculopathy: a case report
}

\author{
Boris Starčević, \\ Mario Udovičić, \\ Hrvoje Falak*, \\ Aleksandar Blivajs, \\ Vanja Ivanović \\ Mihajlović, \\ Petra Vitlov
}

University Hospital Dubrava, Zagreb, Croatia
KEYWORDS: allograft vasculopathy, heart transplantation, percutaneous coronary intervention, retransplantation.

CITATION: Cardiol Croat. 2018;13(1-2):38. | https://doi.org/10.15836/ccar2018.38

*ADDRESS FOR CORRESPONDENCE: Hrvoje Falak, Klinička bolnica Dubrava, Av. G. Šuška 6, HR-10000 Zagreb, Croatia. / Phone: +385-99-8181-818 / E-mail: hrvoje.falak@gmail.com

ORCID: Boris Starčević, https://orcid.org/0000-0002-3090-2772 • Mario Udovičić, http://orcid.org/0000-0001-9912-2179 Hrvoje Falak, http://orcid.org/0000-0002-6502-683X • Aleksandar Blivajs, http://orcid.org/0000-0003-3404-3837 Vanja Ivanović Mihajlović, https://orcid.org/0000-0001-6931-5404 • Petra Vitlov, https://orcid.org/0000-0001-6983-1409

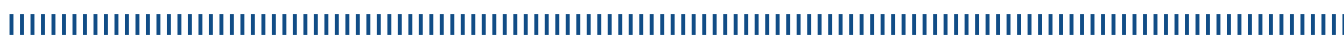

Cardiac allograft vasculopathy (CAV) is a major cause of morbidity and mortality after the first year of heart transplantation. It is characterized by progressive, concentric intimal hyperplasia and has a prevalence approaching 50\% within the first 10 years after transplantation ${ }^{1}$.

We report a case of a male patient who in 2007 at the age of 30 years underwent a heart transplantation due to dilated cardiomyopathy. Seven years later, during routine coronary angiography he was diagnosed with diffuse CAV. In follow-up angiographies successive progression of CAV was observed, despite modification of medical treatment, and it mandated percutaneous coronary intervention (PCI) with implantation of 3 drug-eluting stents (DES) in the left anterior descending artery, the circumflex coronary artery and the right coronary artery, culminating with a successful PCI with implantation of a further DES in left main coronary artery in 2016. Finally, in April 2017 he underwent a successful cardiac retransplantation.

PCI is a feasible bridging strategy for coronary lesions associated due to $\mathrm{CAV}^{1}$, which includes unprotected PCI for the left main coronary artery stenosis, however the only definitive treatment for CAV is retransplantation.
RECEIVED:

February 4, 2018

ACCEPTED:

February 10, 2018

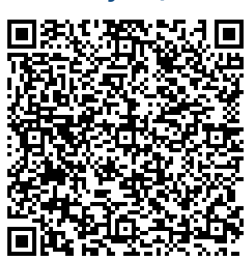

$\square$ Cardiologia Croatica 2018;13(1-2):38.

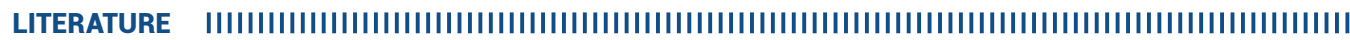

1. Lee MS, Finch W, Weisz G, Kirtane AJ. Cardiac allograft vasculopathy. Rev Cardiovasc Med. 2011;12(3):143-52. PubMed: https://www.ncbi.nlm.nih.gov/pubmed/22080925 